\title{
Interest of Surgical Treatment of Per-Trochanteric Fractures by Gamma Nail: About 100 Cases
}

\author{
Omar Mourafiq ${ }^{*}$, Youssef Benyias, Hicham Benomar, Valery Kamenan, Jalal Boukhriss, \\ Bouchaib Chefry, Ahmed Salim Bouabid, Driss Bencheba, Moustapha Boussouga
}

\begin{abstract}
Gamma nail closed osteosynthesis has surpassed several methods previously used in the treatment of fractures in the trochanteric region.

The objective of the research was to carry out an epidemiological study and to assess the evolutionary profile of patients with per-trochanteric fracture treated with gamma nail.

Materials and methods. In this retrospective study, we report the experience of the Traumatology-Orthopedics Service II of the Military Teaching Hospital Mohamed V-Rabat, in the treatment of per-trochanteric fractures by gamma nail in 100 cases, collected between January 2011 and March 2016.

Results. The average age of our patients was 68 years, with a male predominance of $67 \%$. The most reported etiology $(92 \%$ of cases) was simple drop. Stable fractures were the most common (81\%), with a predominance of simple per-trochanteric fractures. The average response time was 24 hours, the average duration of the surgical procedure was 45 minutes. The rate of infectious complications was $1 \%$; the rate of mechanical complications was $1 \%$. The functional results were excellent and good in $95 \%$ of cases. The average consolidation time was 8 weeks.

Conclusions. Trochanteric fracture is a delayed emergency which is seen primarily in the elderly. The gamma nail represents one of the latest improvements in implants for the treatment of these fractures. We report a series of 100 cases of trochanteric fractures treated surgically by gamma nail. The functional results were very encouraging compared to those reported in the literature.
\end{abstract}

Keywords

fractures; osteosynthesis; gamma nail; trochanteric

Department of Orthopaedic Surgery \& Traumatology II, Mohamed V Military Hospital, Rabat 10000, Morocco

Faculty of Medicine and pharmacy, Rabat 10000, Morocco

Mohamed V University, Rabat 10000, Morocco

*Corresponding author: omarmourafiq24@gmail.com

\section{Problem statement and analysis of the latest research}

The trochanteric fracture is a delayed surgical emergency, ideally to be operated within the first 48 hours.

The osteosynthesis by nail Gamma is a technique which is not very hemorrhagic and mechanically stable. It privileges this character due to the quality of reduction in open methods including hemorrhagic complications, mechanical and septic ones [1].

\section{Materials and methods}

The authors report a retrospective study of 100 cases of trochanteric fracture, operated by Gamma nail. These patients were trained in the Trauma-Orthopedics Service II of the Military Teaching Hospital Mohamed V, over a period of five years, from January 2011 to March 2016. The study methods were based on the use of medical records with the collection of clinical examination data, radiological, surgical and evolutionary data in these patients.

\section{Results}

The average time of the intervention was 24 hours, this allowed the conditioning of the patient. The intervention was 80 times under spinal anesthesia and 20 times under general anesthesia. The average duration of the intervention was 45 min. All the nails used in our series had a $130^{\circ}$ angulation with a diameter of $11.5 \mathrm{~mm}$ (Fig. 1). For one patient, long gamma nail was used because the patient had a fracture of the ipsilateral femoral diaphysis (Fig. 2)

The quality of the osteosynthesis is judged by the position riof the cervical screw in the head, the face and profile shots, considering that the best position was inferior to face and median to profile coming to support the primary compression spans.

During the evolution, all our patients were put in load early during the first 24 hours. There were five types of postoperative complications: a case of septic complication 
that has evolved well under antibiotherapy and local care, a case of thrombophlebitis controlled by heparin therapy, three cases of glycemic imbalances treated with insulin therapy and a case of slippage syndrome treated by rehydration, parenteral nutrition and antidepressant treatment.

Bone healing was achieved within two months. The functional result was considered excellent and good in 95\%, average in $5 \%$ of cases.

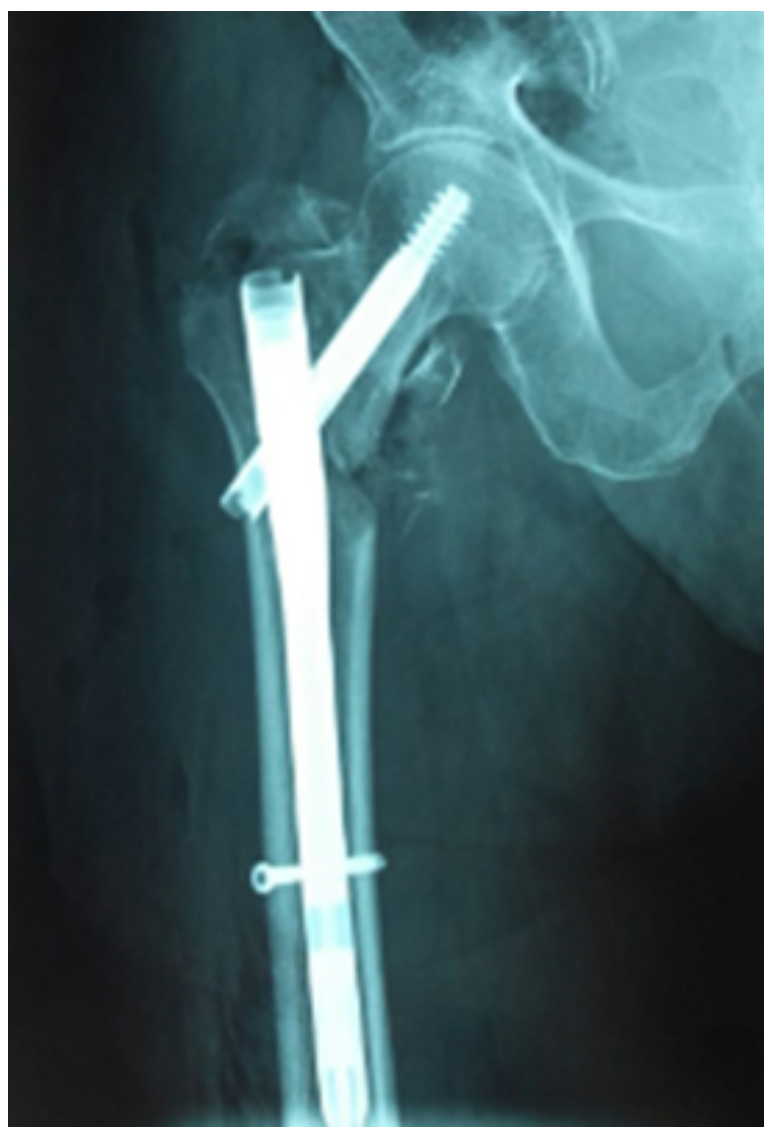

Figure 1. Radiography of the right hip face showing a complex right per-trochanteric fracture treated with gamma nail

\section{Discussion}

Trochanteric fractures account for $65 \%$ of hip fractures. These fractures keep a serious prognosis with more than $20 \%$ of deaths annually [2].

The average age in our series was 64; it is a relatively young age. In our series there was a predominance of trochanteric fractures in the male sex $(65 \%)$, while the foreign literature found a predominance of the female sex [3]. This was due to the recruitment mode of our military training. Osteosynthesis of trochanteric fractures by gamma nail relative to a plate was attached to the lateral cortex. Bending forces were greatly reduced in favor of compression forces at the fracture site while avoiding cephalic protrusion of the material [4].

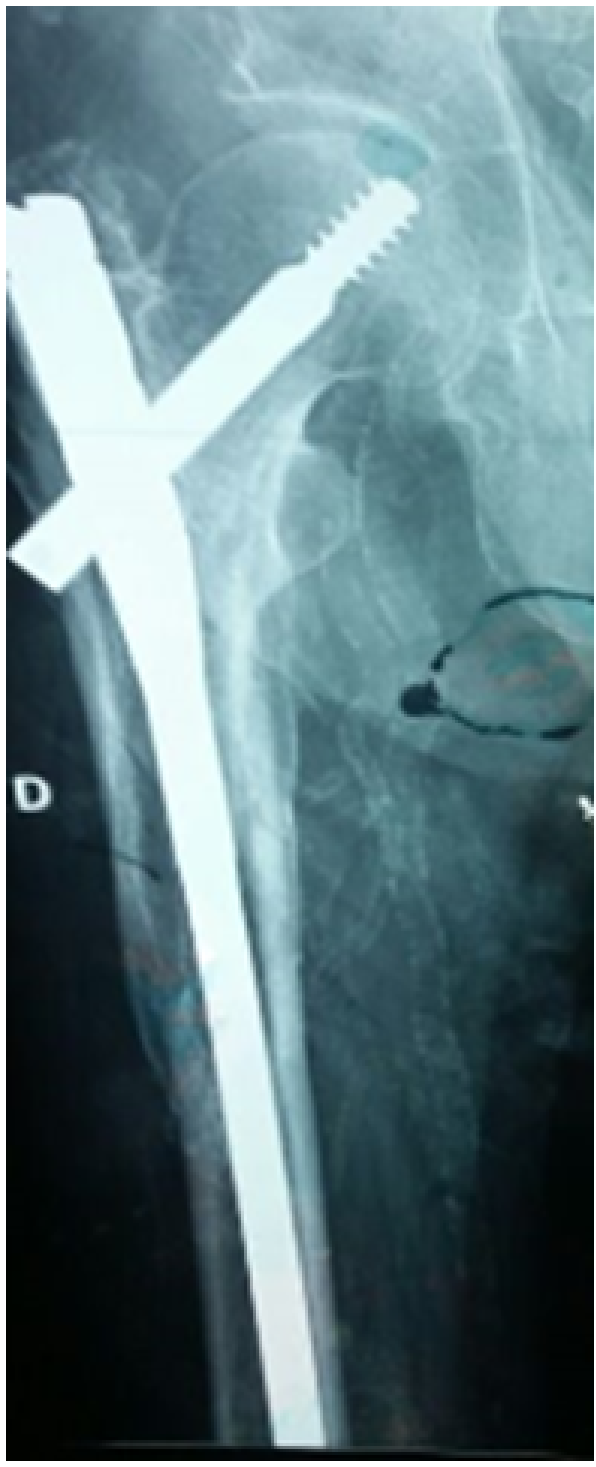

Figure 2. Radiography of the right hip face showing right per-trochanteric fracture associated with ipsilateral diaphyseal fracture, treated with long gamma nail

In our series, the average duration of the intervention was $45 \mathrm{~min}$. In study conducted by for Kempf, the average duration of the intervention was 41 minutes [3]. The intramedullary nailing type gamma nail was equipped with a powerful ancillary which facilitated the implant placement. This gave a speed to the operative procedure being beneficial for the patient and the surgeon who is less exposed to irradiation. According to the majority of authors $[3,5]$, surgical treatment of trochanteric fractures should be undertaken urgently (one to three days). Any delay in the intervention had an impact on the mortality and morbidity rate associated with this type of fracture $[6,7]$. The response time in our study was comparable to other series. According to Kempf [3], the optimum time to operate such fractures was the day after admission.

In our series, the support was done within 24 hours postop- 
eratively. According to various authors using the gamma nail, the support rate during the first week was very high, ranging between $82 \%$ and $92.4 \%[3,8]$.

In our series, consolidation was obtained in delays comparable to those of the literature (8 weeks) $[3,9]$.

\section{Conclusions}

Fractures of the trochanteric massif is a real fact of society explained by the steady increase in life expectancy and the weakening osteopathy that accompanies it. Osteosynthesis by gamma nail ensures a stable and solid reduction adapted to all the unstable fractures of the trochanteric region, and their diaphyseal irradiation, as well as a normal bone as pathological, thus allowing an early resumption of the support.

\section{References}

[1] Penot P, Bezon E, Lenen D. Osteosynthesis of trochanteric fractures. About 390 fractures. Journal of Orthopedic Surgery. 1992;171.

[2] Baudoin C, Rardellone P, Mer F, Sebert JL. Devenir à court et à moyen terme (2 ans) des fractures de l'extrémité supérieure du fémur. Analyse des différentes conséquences. Collection of locomotor pathology. Paris: Masson; 1991;217-220.

[3] Kempf I, Grosse A, Taglang G. The Gamma nail in the treatment of trochanteric fractures: Indications and results, a study of 121 cases. Rev Chir Orthop Reparatrice Appar Mot. 1993;79(1):29-40. [published in French]

[4] Boukhriss J, Boussouga M, Jaafar A et al. Interest of the surgical treatment of fractures of the trochanteric mass by gamma nail, about 84 cases. Pan Afr Med J. 2014;19:6. [5] [published in French] DOI: https://doi.org/ $10.11604 /$ pamj.2014.19.6.3190

[5] Forthomme JP, Costenoble V, Soete P, Docquier J. Treatment of trochanteric fractures of the femur using the gamma nail (apropos of a series of 92 cases). Acta Orthop Belg. 1993;59(1):22-29. [published in French] [PMid:8484318]

[6] Hadounne AR, Messoudi A, Nechad M et al. Les fractures sous trochantériennes à propos de 42 cas. Rev Maroc Chir Orthop Trauma 2006;27:18-21.

[7] Scheerlinck T, Haentjens P. Fractures of the upper end of the femur in adults. EMC - Appareil locomoteur. 2003;1(1):10-23. [published in French]

[8] Pibarot V, Bejui-Hugues J. Fractures of the trochanteric mass (femoral prosthesis excepted). Encycl Méd Chir. 2001;13:44-620.
[9] Badila AE, Radulescu R, Nutiu O et al. Gamma nail versus DHS in the treatment of trochanteric fractures. Journal of orthopedic surgery and traumatological. 2004;90(5):1181. [published in French]

Received: 2018-11-03

Revised: 2018-12-01

Accepted: 2018-12-01 